\title{
Morphogenesis signaling components influence cell cycle regulation by cyclin dependent kinase
}

\author{
Brian TD Tobe*1,2, Ana A Kitazono ${ }^{3}$, Jacqueline S Garcia1 ${ }^{1}$, Renee A Gerber ${ }^{1}$, \\ Brooke J Bevis ${ }^{1}$, John S Choy ${ }^{1}$, Daniel Chasman ${ }^{4}$ and Stephen J Kron ${ }^{1}$
}

\begin{abstract}
Address: ${ }^{1}$ Ludwig Center for Metastasis Research, University of Chicago, Chicago, IL 60637, USA, ${ }^{2}$ Department of Psychiatry, University of California-San Diego, San Diego, CA 92093, USA, ${ }^{3}$ Department of Biochemistry and Cellular and Molecular Biology, University of Tennessee, Knoxville, TN 37996, USA and "Brigham and Women's Hospital, 900 Commonwealth Avenue, Boston, MA 02115, USA

Email: Brian TD Tobe* - briantobe@yahoo.com; Ana A Kitazono - akitazon@utk.edu; Jacqueline S Garcia - jksuen@midway.uchicago.edu; Renee A Gerber - rgerber@law.harvard.edu; Brooke J Bevis - bevis@wi.mit.edu; John S Choy - choyj@mail.nih.gov;

Daniel Chasman - dchasman@rics.bwh.harvard.edu; Stephen J Kron - skron@uchicago.edu

* Corresponding author
\end{abstract}

Published: I July 2009

Cell Division 2009, 4:12 doi:10.1186/1747-1028-4-12
Received: 13 March 2009

Accepted: I July 2009

This article is available from: http://www.celldiv.com/content/4/I/I2

(C) 2009 Tobe et al; licensee BioMed Central Ltd.

This is an Open Access article distributed under the terms of the Creative Commons Attribution License (http://creativecommons.org/licenses/by/2.0), which permits unrestricted use, distribution, and reproduction in any medium, provided the original work is properly cited.

\begin{abstract}
Background: The yeast cell cycle is largely controlled by the cyclin-dependent kinase (CDK) Cdc28. Recent evidence suggests that both CDK complex stability as well as function during mitosis is determined by precise regulation of Swel, a CDK inhibitory kinase and cyclin binding partner. A model of mitotic progression has been provided by study of filamentous yeast. When facing nutrient-limited conditions, Ras2-mediated PKA and MAPK signaling cascades induce a switch from round to filamentous morphology resulting in delayed mitotic progression.
\end{abstract}

Results: To delineate how the dimorphic switch contributes to cell cycle regulation, temperature sensitive cdc28 mutants exhibiting constitutive filamentation were subjected to epistasis analyses with RAS2 signaling effectors. It was found that Swe I-mediated inhibitory tyrosine phosphorylation of Cdc28 during filamentous growth is in part mediated by Ras 2 activation of PKA, but not KssIMAPK, signaling. This pathway is further influenced by Cks I, a conserved CDK-binding partner of elusive function with multiple proposed roles in CDK activation, transcriptional regulation and ubiquitin-mediated proteasome degradation.

Conclusion: The dynamic balance between $\mathrm{Cks}$ - and Swe I-dependent regulation of Cdc28 and, thereby, the timing of mitosis during yeast dimorphism is regulated in part by Ras $2 / \mathrm{cAMP}$-mediated PKA signaling, a key pathway controlling filamentous growth.

\section{Background}

Yeast cell division is tightly coupled to morphology. Progression through mitosis activates an apical-isotropic switch in which polarized bud growth is redirected to produce round daughter cells [1]. Conversely, mitotic delay results in filamentous growth allowing spreading away from the colony center. Thus, filamentation may be elic- ited by mutations in mitotic regulators such as the cyclindependent kinase (CDK) Cdc28 or its mitotic cyclin binding partner $\mathrm{Clb} 2$ [2-4]. Cdc28/Clb2 complexes phosphorylate hundreds of effectors containing S/TP sites, preferably (S/T)PX(K/R), including mitotic spindle components, signaling proteins and other cell cycle regulators $[5,6]$. 
The switch from round to filamentous growth is stimulated physiologically by environmental conditions including low nitrogen availability or fusel alcohol exposure [7]. Although it has been hypothesized that these stimuli impinge on CDK and/or its regulators, no clear mechanism has emerged. Extracellular signals are conveyed through a member of the highly conserved RAS GTPase family, Ras2. Deletion of RAS2 diminishes filamentation, while the dominant allele RAS2-VAL19 induces constitutive pseudohyphal differentiation [2]. Ras2 activates both the Sterile (Ste) Mitogen-Activated Protein Kinase (MAPK) and the Protein Kinase A (PKA) - CAMP cascades [8]. The MAPK pathway involves sequential activation of the PAK kinase Ste20, the MAPKKK Ste11, the MAPKK Ste7 and the MAPK Kss1, culminating in the activation of the transcription factors Tec1 and Ste12 $[9,10]$. Accordingly, overproduction of Tec1 induces filamentation [11], while deletion of TEC1 decreases filament formation [12]. On the other hand, in the PKA pathway, the PKA subunit Tpk2 specifically activates filamentation by activation of the transcription factor Flo8 and inhibition of the transcriptional repressor Sfl1 $[13,14]$. Deletion of FLO8 diminishes filamentation, whereas deletion of SFL1 enhances filamentation [12]. Production of cAMP is opposed by phosphodiesterases Pde1 and Pde2 which when overexpressed reverse some RAS2-V19 phenotypes $[15,16]$.

One possible target of Ras2 signaling may be the Wee kinase Swe1. Swe1 inhibits Cdc28-Clb2 activity at G2/M via phosphorylation of Cdc28 Tyr19 and a phosphorylation-independent mechanism [17]. Overexpression of Swe1 or stabilization of Swe1 delays mitosis and promotes cell elongation and hyperfilamentation [17-19]. Tyrosine-19 may make direct contact with ATP [20], and it is thought that phosphorylation and even binding by Swe1 impedes ATP utilization by Cdc28. In turn, initial Swe 1 phosphorylation by Cdc28/Clb2 complexes stabilizes its interaction with Cdc28, potentiating further inhibition. Inhibition is alleviated by Mih1, a CDK tyrosine phosphatase, which reactivates Cdc28 to hyperphosphorylate Swe1 leading to its dissociation from CDK complexes [21]. Swe1 is also controlled by the Nim1 kinase Hsl1. Deletion of HSL1 results in increased Cdc28 tyrosine-19 phosphorylation [22] and enhanced filamentation $[17,18]$, whereas overexpression of HSL1 leads to diminished Swe1 protein levels [23]. Further, deletion of HSL1 restores filamentation in the absence of FLO8 and to a lesser degree TEC1, but not in flo8 tec1 double mutants [18]. This suggests that PKA has greater specificity for Swe1 inhibition of Cdc28.

PKA has also been shown to mediate Ras2 and glucosedependent inhibition of the anaphase-promoting complex (APC) $[24,25]$. The APC is a ubiquitin-protein ligase complex that functions to target proteins for destruction by the proteasome [26]. Overexpression of both the APCactivator $C D C 20$ as well as negative regulators of the PKA pathway PDE2 and BCY1 were found to suppress the temperature sensitivity of a cohesin mutant [27]. Further analysis showed that inhibition of PKA also suppressed temperature sensitivity of $c d c 16-1$ mutant defective in APC function [27]. Together these studies indicate the possibility that PKA may negatively regulate the APC. Such a mechanism may further separate the role of PKA from Kss1-MAPK in the regulation of filamentous growth.

Importantly, Cdc28 is also intimately linked to APC activation. Cdc20-dependent APC activity during mitosis is positively regulated via phosphorylation by Cdc28 [28]. Reduced binding of Cdc20 to the APC has been observed in the presence of $c d c 28-Y 18 \mathrm{~V}, T 19 \mathrm{~F}$, a mutant resistant to Swe1 mediated phosphorylation [28]. Further, the CDK subunit Cks1 is required for transcription of CDC20. The precise mechanism remains obscure but has been proposed to involve Cks1 recruitment of the proteasome to Cdc28 complexes [29]. Cks1 has been shown to physically interact with proteasome subunits [30]. Interestingly, while certain cks1 temperature-sensitive alleles confer G2/M delay [31], Clb cyclin-Cdc28 complexes do not require Cks 1 for normal kinase activity $[31,32]$.

To further elucidate the pathway by which extracellular signals impinge on cell cycle, we screened for temperature sensitive $c d c 28$ mutants that perform enhanced filamentous growth. A preponderance of the mutations localized to the binding region of Cks 1 . We examined the genetic interactions of these mutants with cell cycle regulators and Ras 2 signaling components. Our results indicate that the PKA-CAMP pathway may be an additional signaling mechanism by which Swe1 inhibition of Cdc28 is affected. However, Swe1 function is downregulated by a mechanism requiring association of Cdc28 with Cks1.

\section{Results}

cdc28 mutants suggest Cksl is a regulator of filamentation We hypothesized that constitutively filamentous $c d c 28$ mutants, which experience growth arrest at elevated temperatures would be valuable tools to identify connections between cell cycle and extracellular signals. Therefore, a $c d c 28$ shuffle strain was created in which homozygous replacement of $C D C 28$ with TRP1 gene was covered by a URA3 marked plasmid harboring CDC28. Transformation of this strain with a library of degenerate-PCR derived $c d c 28$ alleles on a HIS3 marked plasmid, followed by negative selection against URA3 allowed screening colonies for mutants exhibiting enhanced filamentous growth on low nitrogen media. Five hundred colonies were selected [3]. Secondary screening of these colonies for those that 
exhibited temperature sensitive growth at $35^{\circ} \mathrm{C}$ revealed 39 mutants with one to five amino acid substitutions.

Cyclin-dependent kinase is a bi-lobed protein with an amino terminal domain composed primarily of $\beta$-sheets and a larger carboxy-terminal domain containing several $\alpha$-helices. Between these two domains lies the catalytic core, the opening of which is covered by the T-loop (activation loop) in the inactive monomeric state [20,33-35]. We have previously modeled Cdc28 based on the crystal structure of the human CDK2 enzyme [3,36]. Mapping the residues modified in the selected mutants on our model revealed that while some fell within the interior of the molecule, many were surface residues predicted to participate in binding to known essential partners (Fig. 1).
Several mutations fell close to or within the ATP binding cleft (Fig. 1, green) and thus near Tyr19, the target of Swe1 mediated phosphorylation. Other mutations fell in the PSTAIRE helix involved in cyclin binding and catalytic function, or the activation loop, a domain involved in substrate recognition that includes Thr169, the target of Cak1 phosphorylation (Fig. 1, red). However, nearly one third of the alleles contained mutations that might impinge on Cdc28 interaction with Cks1 by altering contact residues, or residues underlying the Cks1 binding surface (Fig. 1, yellow and orange).

We were struck by the high number of mutations potentially affecting Cks1 binding, as this factor had yet to be directly linked to the apical-isotropic switch or filamen-

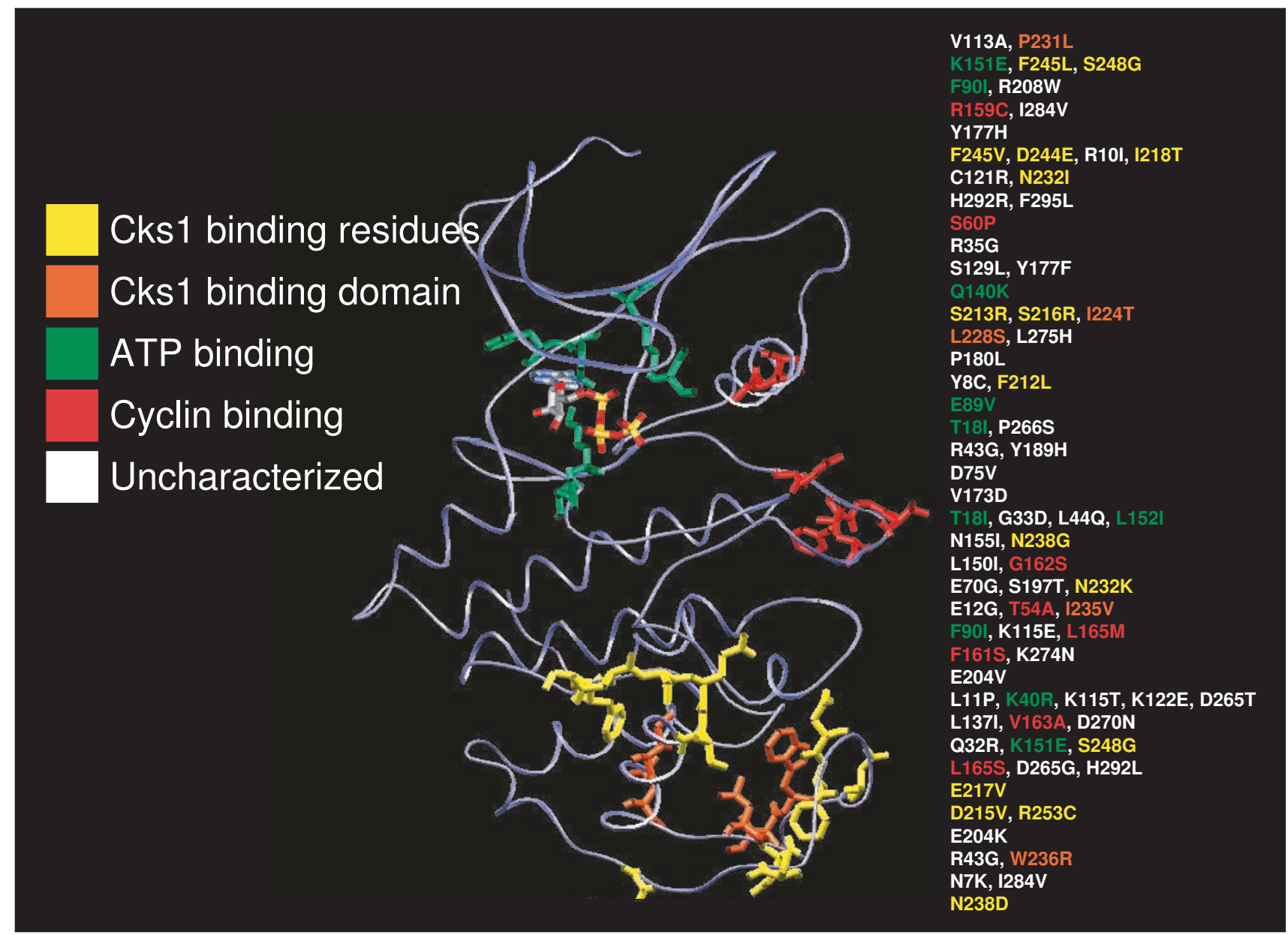

\section{Figure I}

Hyper-filamentous, temperature sensitive cdc28 mutants exhibit altered Cks I-binding region. The three-dimensional structure of $\mathrm{Cdc} 28$ was modeled from the crystal structure of human CDK2 [3]. Each allele is listed with amino acid substitutions color coded according to the functional region of the molecule in which it lies: yellow = Cks I binding, orange $=$ nonsurface residues underlying the CksI-binding domain, green = ATP-binding, red = cyclin-binding, white = uncharacterized structure function relationship, striped = ATP. 
tous differentiation. We examined if normal growth could be restored in these mutants by high copy CKS1. Indeed, 11 out of 15 alleles exhibited improved growth by CKS1 overexpression (Table 1). Of the 11 mutants suppressed by CKS1, four exhibited near wild type restoration of growth and morphology (1). The point mutants $c d c 28$ $E 217 \mathrm{~V}$ and $c d c 28-\mathrm{N} 238 \mathrm{D}$ were in this category suggesting that these alterations were less likely to directly affect additional partner associations. Although both mutations lie in the Cks1 binding region, co-crystal studies of the CDK2-Cks1 interface have demonstrated a direct contact only for the residue analogous to Cdc28 Glu217 with residues Glu63 and His94 in Cks1 [37]. Importantly, our bioinformatic analysis using algorithms designed by Chasman and Adams for assessment of the functional consequences of amino acid substitutions [38], indicated that mutation of residue E217 to valine should not otherwise affect the structure of monomeric Cdc28 (data not shown). E217 falls in the highly conserved GDSEID (214-219) motif, previously implicated in Cdc28 binding to Cks1 [39]. Mutations in residues 212, 213, and 215218 were also identified by this screen, indicating that this domain of Cdc2 8 is particularly important for regulating morphological differentiation (Fig. 1).

To better study the genetic interactions of $c d c 28-E 217 \mathrm{~V}$, we performed genomic replacement of endogenous CDC28 with $c d c 28-E 217 \mathrm{~V}$. As expected, transformation of $c d c 28-E 217 V$ with high copy CKS1 similarly relieved mutant phenotypes as previously found in the $c d c 28$ E217V shuffle strain (Fig. 2A). We also observed decreased pull-down of Cdc28-E217V compared to wild-type Cdc28 with beads coupled to the $S$. pombe Cks1 homolog p13 Suc1, under conditions of saturating amounts of Cdc28 and Cdc28-E217V proteins (Fig. 2B). These data strongly suggest a loss of association of Cdc28 with its essential partner Cks 1 as the basis for the temperature sensitivity in this mutant. Cdc28-E217V also showed normal Cdc28 protein abundance and levels of Clb2- associated histone H1 kinase activity at permissive and restrictive tempera-

Table I: Genetic comparison of temperature sensitive alleles containing mutations in the Cks I binding domain

\begin{tabular}{|c|c|c|}
\hline Cks I Binding Domain Mutations & Suppression by CKSI overexpression & Suppression by flo8 \\
\hline $\mathrm{VII} A \mathrm{~A}, \mathrm{P} 23 \mathrm{IL}$ & + & - \\
\hline KI5IE, F245L, S248G & + & - \\
\hline F245V, D244E, RI0I, I2I8T & ++ & - \\
\hline $\mathrm{Cl} 2 \mathrm{IR}, \mathrm{N} 232 \mathrm{I}$ & - & - \\
\hline S213R, S216R, I224T & - & - \\
\hline L228S, L275H & + & - \\
\hline Y8C, F2I LL & + & + \\
\hline NI55I, N238G & + & + \\
\hline E70G, S197T, N232K & ++ & + \\
\hline EI2G, T54A, 1235V & - & + \\
\hline Q32R, KI5IE, S248G & - & - \\
\hline $\mathrm{E} 217 \mathrm{~V}$ & ++ & + \\
\hline $\mathrm{D} 215 \mathrm{~V}, \mathrm{R} 253 \mathrm{C}$ & + & + \\
\hline R43G, W236R & + & - \\
\hline N238D & ++ & + \\
\hline
\end{tabular}

HIS3-marked plasmids (pRS413) containing temperature sensitive $c d c 28$ alleles were introduced into a CDC28 shuffle strain. Transformants were subjected to 5-FOA treatment to evict the wild type copy of $C D C 28$ and assayed for growth at $25^{\circ} \mathrm{C}$ and $35^{\circ} \mathrm{C}$. If growth of a given allele was significantly improved by deletion of FLO8 or by overexpression of CKSI, then suppression is indicated by "+". A sign of "-" indicates no change. 
$\Delta$

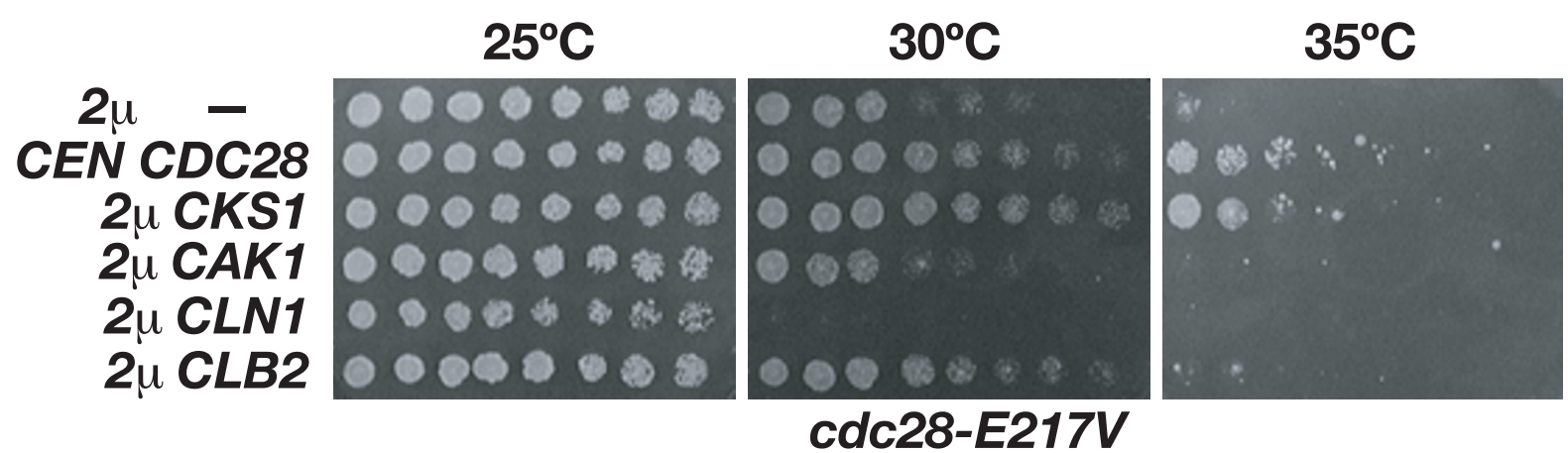

\section{$\stackrel{2 \mu}{C E N} \overline{C D C 28}^{-}$ \\ $2 \mu$ CKS1 \\ 2u CAK1 \\ $2 \mu C L N 1$ \\ $2 \mu C L B 2$}
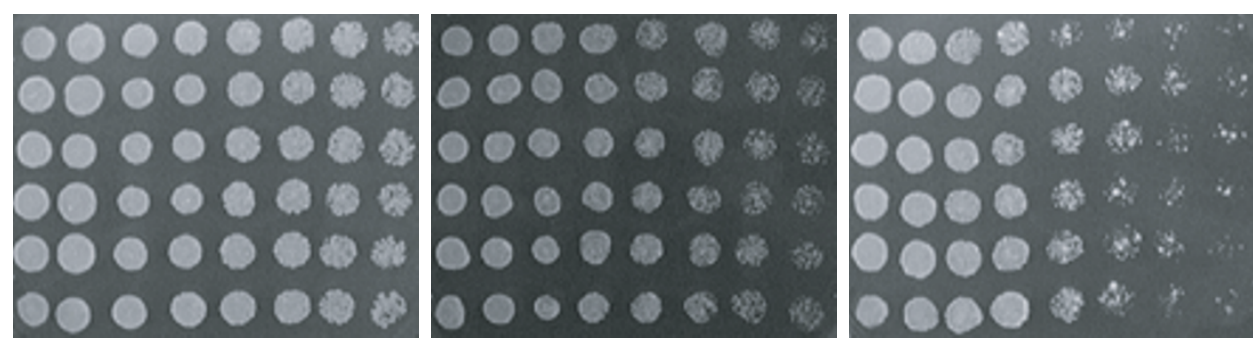

Wild type

B

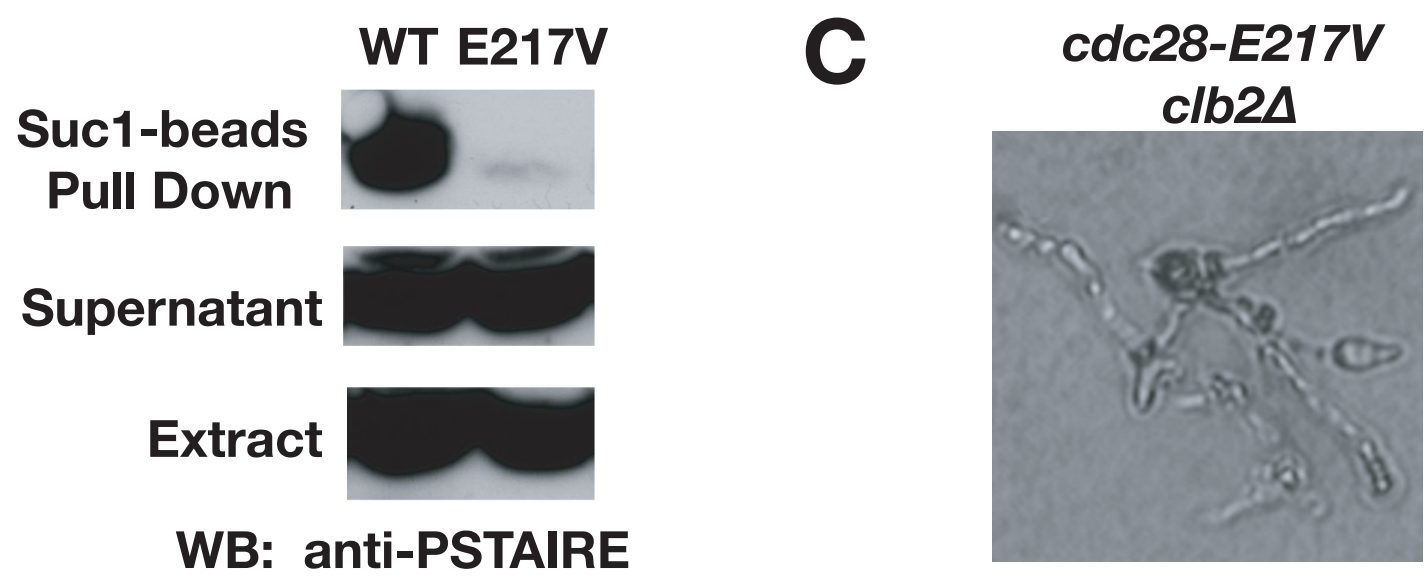

Figure 2

cdc28-E2 I $7 V$ cells exhibit specific genetic interactions with cell-cycle regulators. A) Growth of cdc28 mutant yeast cells containing genomic substitution of E2I7V transformed with high-copy plasmids harboring CKSI, CAKI, CLNI, CLB2 or no insert, or a centromeric plasmid harboring $C D C 28$. B) $\mathrm{pl}^{\text {Sucl }}$ beads-pull downs using yeast protein extract prepared from wild-type or cdc28-E2 I $7 \mathrm{~V}$ at $30^{\circ} \mathrm{C}$. Blots were probed with anti-PSTAIRE CDK antibody. C) Inviability and elongated morphology of clb2 cdc28-E2 I $7 \mathrm{~V}$ double mutant segregants. 
tures (data not shown), in accordance with previous reports indicating that Cks1 does not affect mitotic CDK kinase activity [32].

However, we further questioned if the defects of this mutant were specifically attributable to its diminished interaction with Cks1. As a means to examine this possibility we tested overexpression of the CDK-activating kinase CAK1 in $c d c 28-E 217 V$ cells. Cak1 is an essential CDK activator that phosphorylates Cdc28 on Thr169 in the T loop to promote kinase activity, substrate accessibility and cyclin binding $[40,41]$. If Cak1 overexpression were to alleviate $c d c 28-E 217 \mathrm{~V}$ defects, it could indicate that $c d c 28-E 217 \mathrm{~V}$ harbors intrinsic defects in CDK function or in interaction with other binding partners or substrates. However, high copy CAK1 neither suppressed nor enhanced $c d c 28$-E217V defects (Fig. 2A). Dephosphorylation of Thr169 has been shown to be likely mediated by phosphatases Ptc2 and Ptc3 [42]. We found that overexpression of PTC2 and PTC3 was similarly toxic to wildtype and $c d c 28-E 217 V$ cells (data not shown). Thus, $c d c 28$ E217V phenotypes are not affected by alteration of activating phosphorylation of Cdc28. This further substantiates that $c d c 28-E 217 V$ defects are specific to interaction with Cks1.

Given the well-established roles of Cln 1 and Clb2 cyclins at the G1/S and the G2/M transitions respectively, as well as their opposing effects on the apical-isotropic switch, we examined modulation of $c d c 28-E 217 \mathrm{~V}$ phenotypes by CLB2 and CLN1. CLB2 overexpression partly restored $c d c 28-E 217 \mathrm{~V}$ growth at semi-permissive temperature (Fig. 2A) while $c d c 28-E 217 \mathrm{~V} \mathrm{clb2}$ double mutant segregants were inviable, germinating to form only elongated, terminal buds (Fig. 2C). In turn, CLN1 overexpression diminished proliferation at semi-permissive temperature (Fig. 2A) while deletion of CLN1 partly restored growth (data not shown). These results further support that the phenotype of $c d c 28-E 217 \mathrm{~V}$ is due to delayed mitotic progression.

\section{Protein Kinase A pathway impinges on Cdc28}

In filamentous growth signaling, Ras 2 activates both the PKA pathway and the Kss1-MAPK cascade [43]. We questioned if $c d c 28-E 217 \mathrm{~V}$ phenotypes were dependent on Ras2 signaling. Deletion of RAS2 restored near wild-type growth and morphology to $c d c 28-E 217 \mathrm{~V}$ cells (Fig. 3A,B). Two transcriptional regulators, Flo8 and Sfl1, function as downstream effectors of the PKA pathway [13]. Deletion of FLO8 partially alleviated both the growth and morphology defects of $c d c 28$-E217V (Fig. 3C,D), whereas deletion of SFL1 showed no effect (Fig. 4A). Deletion of TEC1, a transcription factor required for MAPK signaling, also did not alter $c d c 28$-E217V growth or morphology (Fig. 4B, C). These results suggested that the Ras2-activated PKA pathway specifically impinged on $c d c 28-E 217 \mathrm{~V}$ through
Flo8. Providing further confirmation of this connection we found that a high-copy plasmid harboring the cAMP phosphodiesterase PDE2, a negative regulator of PKA, suppressed $c d c 28-E 217 \mathrm{~V}$ defects (data not shown) $[44,45]$.

It has also been reported that the PKA pathway, but not the Kss1-MAPK cascade, may be required for activation of filamentation during amino acid starvation by the transcription factor Gcn4 [46]. In accordance, we observed that deletion of GCN4 provided some suppression to $c d c 28-E 217 \mathrm{~V}$ cells (Fig. 3E). As a final test we reexamined each of the Cks1-binding mutants for genetic interaction with FLO8. Interestingly less that half of these mutants were suppressed by deletion of FLO8 (Table 1). These observations indicate that the interaction of PKA through Flo8 with Cdc28 may be highly specific to a particular mechanism of $\mathrm{CDK}$ regulation.

\section{Swel is modulated by PKA and CksI}

These results supported the Ras2-activated PKA pathway via Flo8 to be an important regulator of Cdc28. Previous genetic evidence by La Valle and Wittenberg suggested that Swe1 regulation of Cdc28 may be an effector of PKA [18]. Therefore, we directly tested if Swe 1 function is modulated by the PKA pathway. We found that deletions of RAS2, FLO8, or the filamentous-growth specific PKA catalytic subunit TPK2 [47] in otherwise wild-type cells each diminished Cdc28 Tyr19 phosphorylation, placing the PKA signaling upstream of Swe1 and Cdc28 (Figure 5A).

Given the relationship between PKA and Swe1, we also tested if $c d c 28-E 217 \mathrm{~V}$ is modulated by SWE1. Strikingly, deletion of SWE1 conferred suppression of both growth and morphology defects of cdc28-E217V (Fig. 5B, C). Again, we asked if these effects were specific to Swe1 or if the absence of any negative regulator of CDK function would improve $c d c 28-E 217 \mathrm{~V}$ defects. Toward examining this question, we observed that deletion of the Cdc28 stoichiometic inhibitor SIC1 had only subtle effects on growth of $c d c 28-E 217 \mathrm{~V}$ cells [48].

One interpretation of these data is that Swe1 functions upstream of Cks1. Nonetheless, arguing against a role for Swe1 binding or Cdc28 Tyr19 phosphorylation in modulating Cks1 binding, Cdc2 8 was pulled down by p13suc1 beads to a similar extent from extracts of cells lacking SWE1 or its opposing phosphatase, MIH1 (Fig. 6A). An alternative explanation is that Cks1 antagonizes Cdc28 binding to or phosphorylation by Swe1. However, GSTSwe1 beads pulled down Cdc28-E217V and wild-type Cdc28 with similar levels, and independent of expression of high copy CKS1. In turn, increased Cdc28 Tyr19 phosphorylation was not detected in the mutant cells (data not 


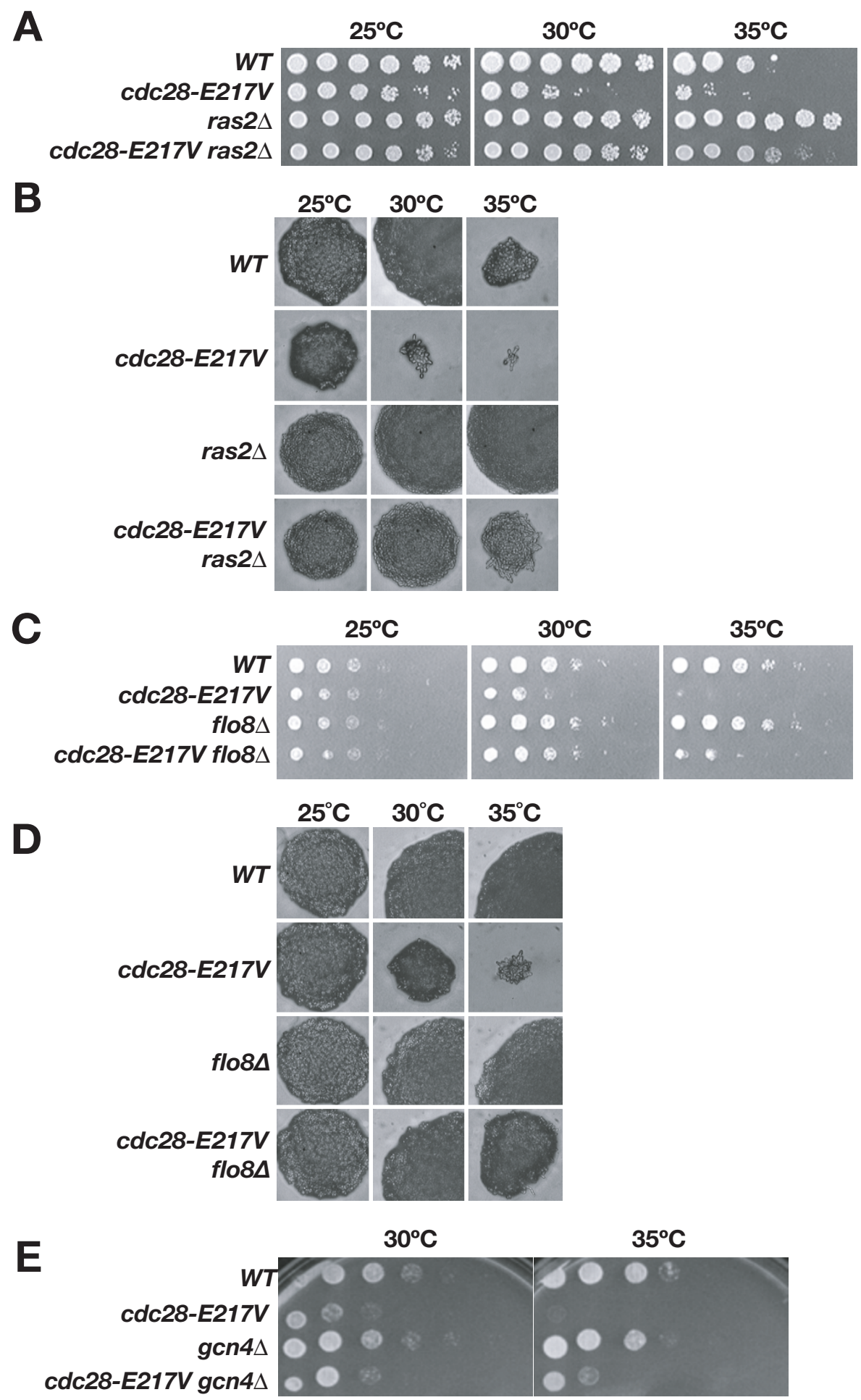

Figure 3

Ras2-mediated PKA pathway impinges on Cdc28. A) Growth and B) Morphology of cdc28-E2 I 7V ras2, wild-type, $c d c 28-E 2$ I $7 \mathrm{~V}$, or ras2 cells growing at 25,30 or $35^{\circ} \mathrm{C}$. C) Growth and D) morphology of cdc28-E2 I $7 \mathrm{~V}$ flo 8 double mutants compared to wild-type, cdc28-E2 I $7 \mathrm{~V}$ and flo8 cells at 25,30 or $35^{\circ} \mathrm{C}$. E) Growth of cdc28-E2 I $7 \mathrm{~V} \mathrm{gcn} 4$ double mutants compared to wild-type, cdc28-E2 $17 \mathrm{~V}$ and gcn 4 cells at $30^{\circ} \mathrm{C}$ and $35^{\circ} \mathrm{C}$. 

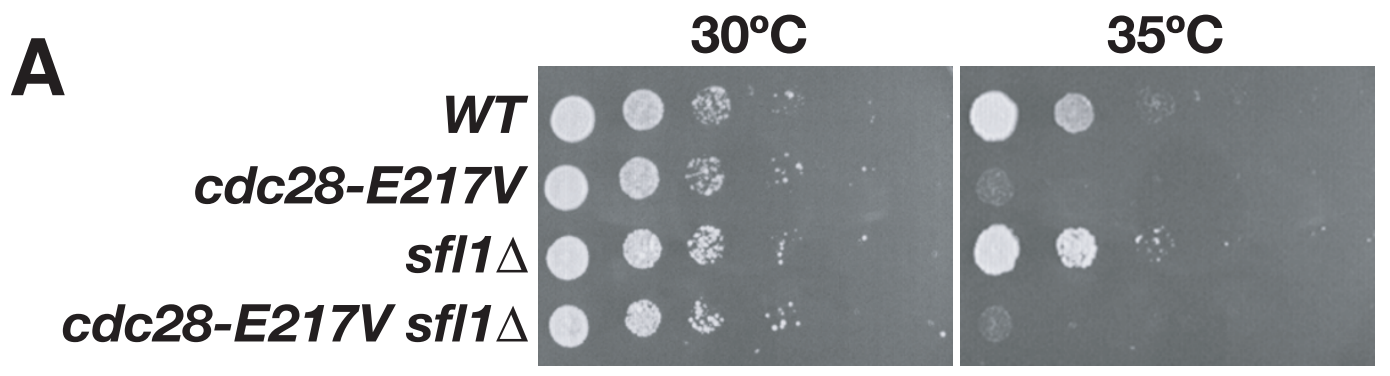

B

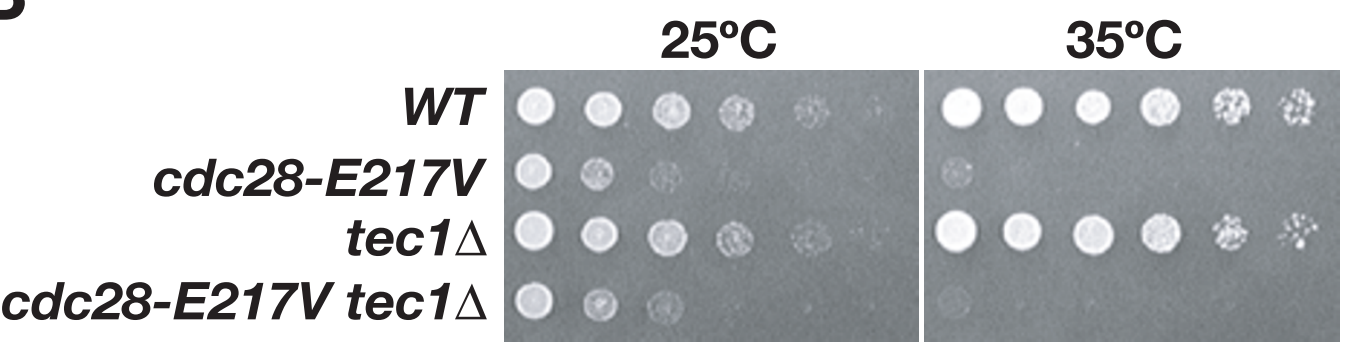

C

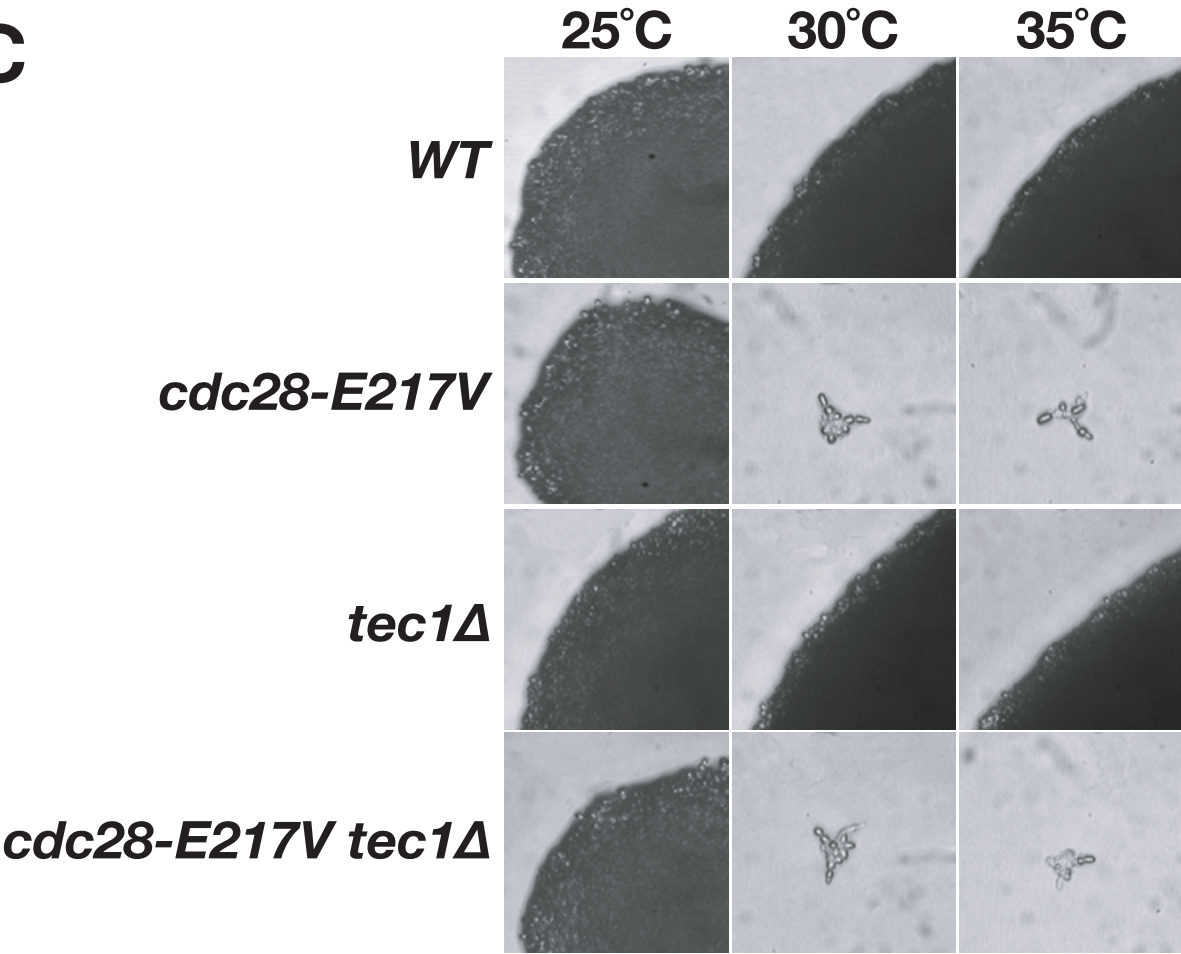

\section{Figure 4}

cdc28-E2 I VV is not affected by deletion of TECI or SFLI. A) Growth of wild type, sflI, cdc28-E2 I 7V strains and sflI cdc28-E2 I $7 V$ double mutants was examined using of 5 -fold serial dilutions of saturated cultures at $30^{\circ} \mathrm{C}$ and $35^{\circ} \mathrm{C}$ B) Growth of cdc28-E2 I $7 \mathrm{~V}$ tecl double mutants compared to wild-type, cdc28-E2 I $7 \mathrm{~V}$ and tecl cells at 25 and $35^{\circ} \mathrm{C}$. C) Effect of deletion of $T E C I$ on morphology of cdc28-E2 I $7 \mathrm{~V}$ at 25,30 or $35^{\circ} \mathrm{C}$. 
A

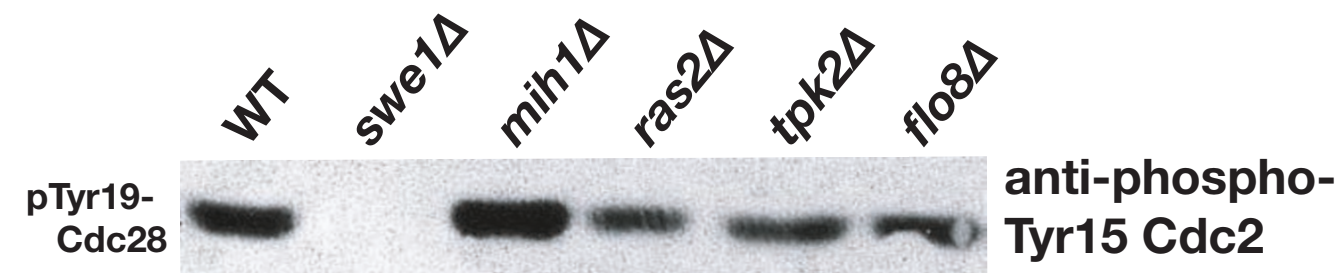

Pho85

Cdc28

anti-PSTAIRE

B

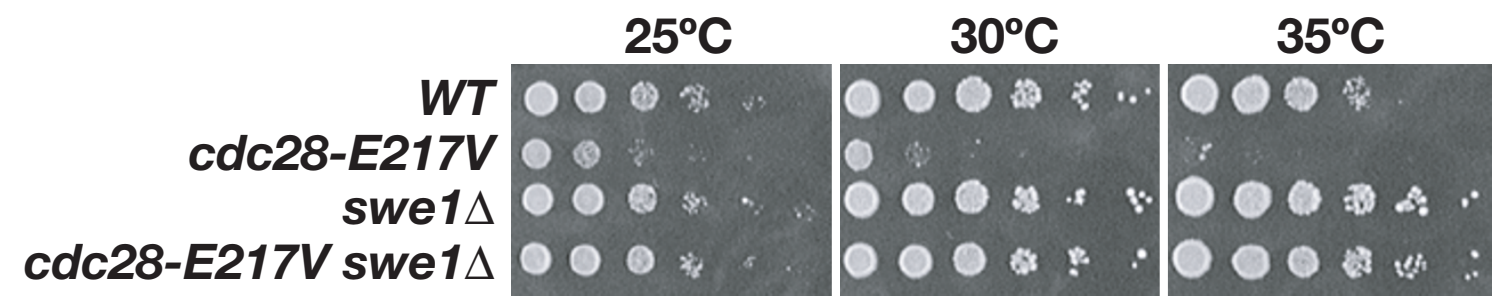

C

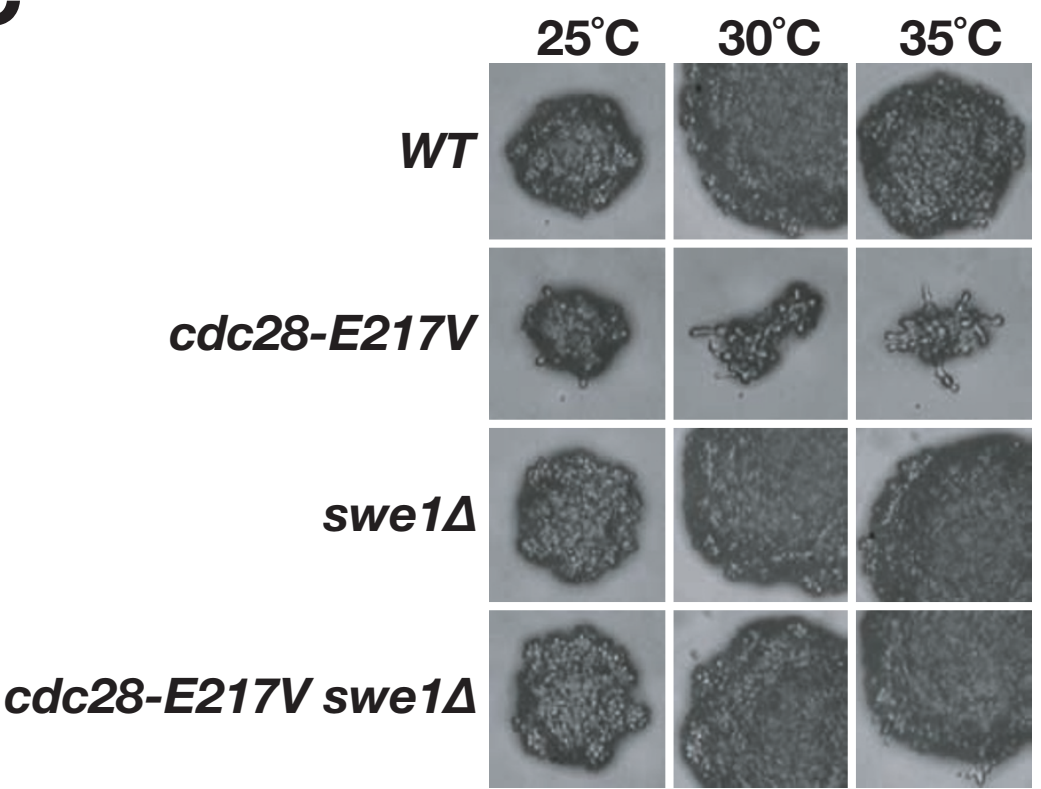

Figure 5

PKA controls Swel regulation of Cdc28. A) Western blot analysis of Cdc28 Tyr 19 phosphorylation in swel, mih I, ras2, tpk2, flo8, or wild-type cells grown to log phase at $30^{\circ} \mathrm{C}$. B) Growth of cdc28-E2 I 7V swel double mutants compared to wildtype, $c d c 28-E 2 I 7 V$ and swe I cells at 25,30 or $35^{\circ} \mathrm{C}$. C) Morphology of $c d c 28-E 2 I 7 V$ swe I double mutants at 25,30 or $35^{\circ} \mathrm{C}$ compared to wild-type, cdc28-E2 I $7 \mathrm{~V}$ and swe I cells. 
A

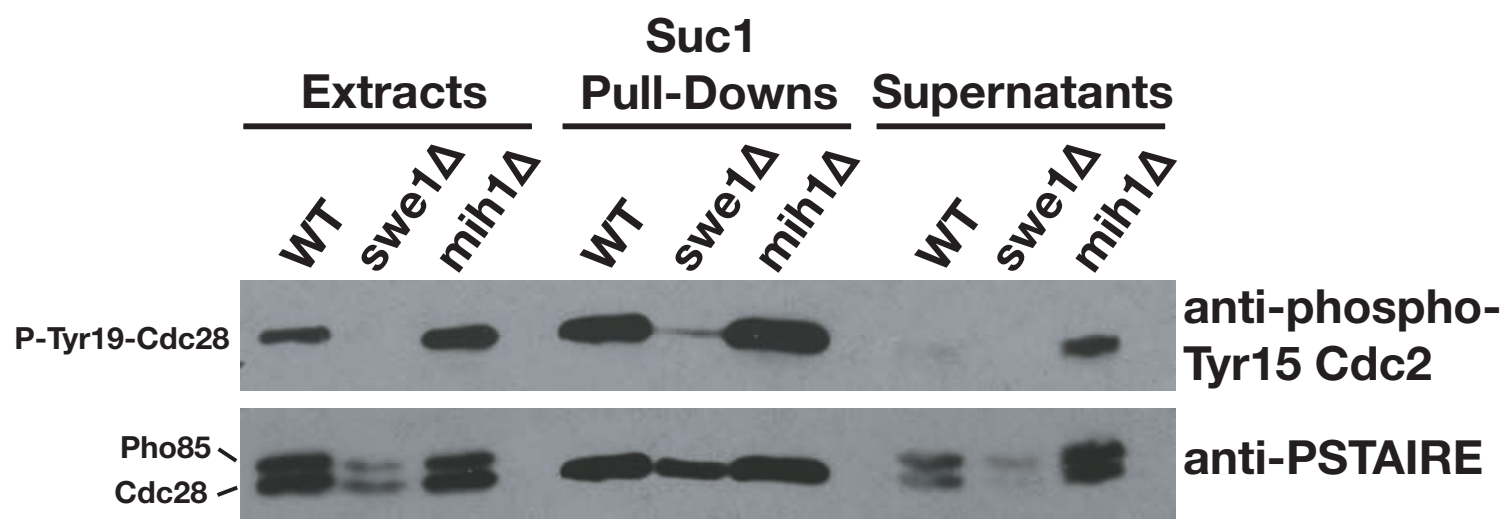

B

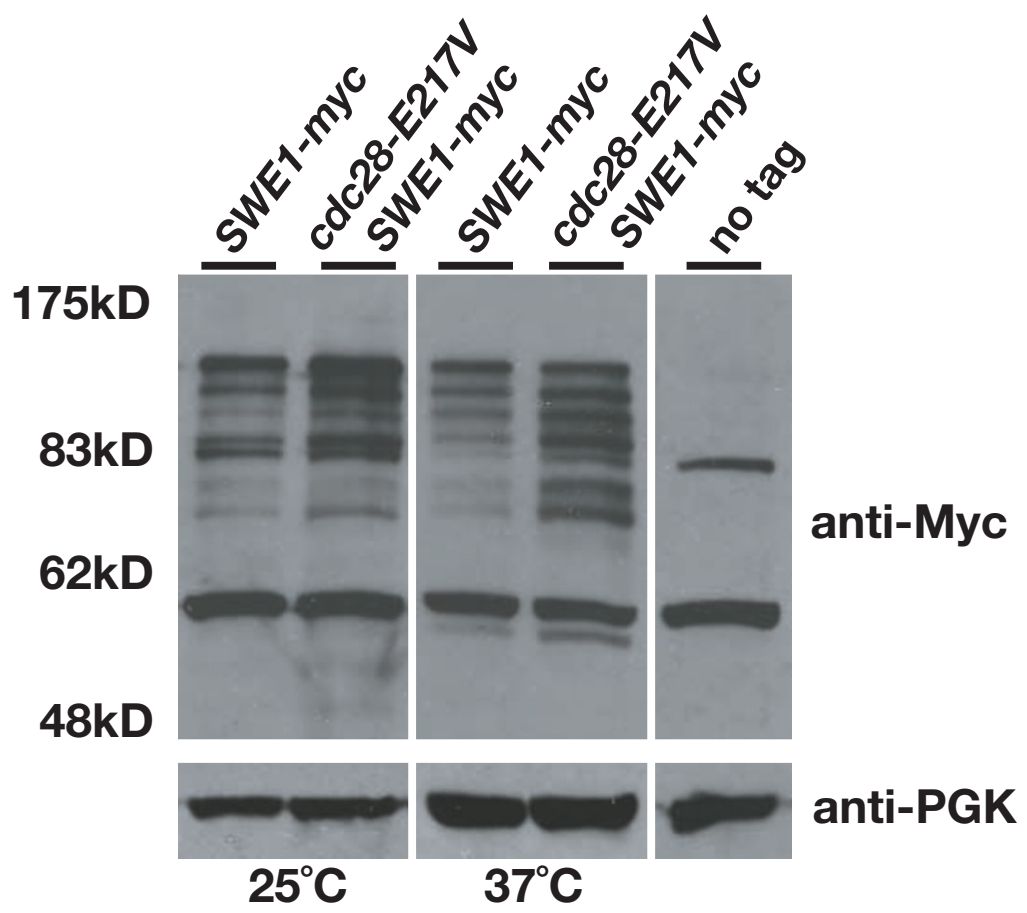

Figure 6

Increased Swe I protein levels mediate cdc28-E2 I 7V defects. A) p I3Sucl beads pull-downs of Tyr I9-phosphorylated and unphosphorylated $\mathrm{Cdc} 28$ from protein extracts prepared from swe I or mih I deletion strains. B) Western blot analysis of Myctagged Swel protein levels from wild-type and cdc28-E2 I $7 \mathrm{~V}$ cells grown to log phase at $25^{\circ} \mathrm{C}$ and shifted to $37^{\circ} \mathrm{C}$, or kept at $25^{\circ} \mathrm{C}$ for $4 \mathrm{~h}$.

shown). Together, these results argue against Swe1 and Cks1 binding competitively to Cdc28.

An alternative link to Cks1 is that Swe1 protein might accumulate and/or persist abnormally in $c d c 28-E 217 \mathrm{~V}$ cells. Western blot analysis of the $c d c 28-E 217 \mathrm{~V}$ cells revealed accumulation of Myc epitope-tagged Swe1, which appeared as a range of apparent molecular weights, a pattern previously ascribed to Swe1 phosphorylation
[49] (Fig. 6B). To further pursue a role for Cks1 in Swe1 function, we examined cells lacking CDC55, a protein phosphatase 2A (PP2A) regulatory subunit that promotes Swe1 degradation. cdc55 mutants contain elevated levels of Swe1 and show morphological defects including slow growth, elongated morphology and increased Cdc28 Tyr19 hyperphosphorylation at $16^{\circ} \mathrm{C}$, which are relieved by deletion of SWE1 [50]. Strikingly, high copy CKS1 also strongly suppressed the growth and morphology defects 
of $c d c 55$ mutants and reduced Cdc28 Tyr19 phosphorylation (Fig. 7A, B, C). These results suggest that Cks1 opposes Swe1 accumulation and inhibitory phosphorylation.

\section{Discussion}

Ras2-mediated signaling has been well studied in filamentous growth. Despite this, the extent of crosstalk between the Ras2-MAPK and Ras2-PKA pathways is uncertain. Although traditionally thought of as parallel pathways [8], there has been some evidence that the Kss 1 MAPK pathway may inhibit the PKA pathway [51] and that Flo8 and Tec1 participate in shared complexes at promoters [52]. Our results indicate that $c d c 28-E 217 \mathrm{~V}$ cells are modulated by the PKA pathway, most likely via FLO8 though the direct targets that mediate this interaction are yet to be established. Deletions of a second downstream component of PKA signaling, SFL1, or the Ras2-MAPK transcriptional effector TEC1 did not show any genetic interaction with $c d c 28-E 217 \mathrm{~V}$. La Valle and Wittenberg have shown that deletion of SWE1 restores filamentous growth to flo8 PKA signaling mutants [18]. Our results extend these findings to suggest the PKA pathway regulates filamentous growth in part by activating Swe1 to phosphorylate Cdc28 Tyr19. Given that $c d c 28-E 217 \mathrm{~V}$ phenotypes partially depend upon the PKA pathway including FLO8, but not the MAPK cascade, we suggest that the regulation of Cdc2 8 by Swe 1 and Cks 1 is likely specifically mediated by PKA.

A paradigm for signaling cascades that culminate in activation of a CDK regulator has been previously observed in the response of haploid yeast to mating pheromone that galvanizes the Ste-MAPK cascade leading to activation of the MAPK Fus3 [53]. Fus3 positively regulates the CDK inhibitor Far1 directly by phosphorylation and indirectly by transcriptional regulation. In turn, Far1 negatively regulates Cln-associated Cdc28 complexes by inhibiting kinase activity and altering its localization [54-56]. Interestingly, Far1 is also subject to a negative feedback loop involving phosphorylation by Cln-associated Cdc28 that is thought to lead to ubiquitination and degradation of Far1 [57]. We have shown that PKA-signaling pathway via Flo8 regulates Swe1-mediated Cdc28 Tyr19 phosphorylation, and that SWE1 mediates $c d c 28-E 217 \mathrm{~V}$ phenotypes. Similarly to Far1, Swe1 is a known Cdc28 substrate [6,22]. Swe1 has been found to make direct contact with the hydrophobic patch of Clb2 initially stabilizing cyclinCdc28 complexes prior to its hyperphosphorylation [58], providing a mechanism for feedback inhibition analogous to that of Far1.

cdc28-E217 cells exhibit increased levels of Swe1 protein. Complex post-translational modification of Swe1 leads to several different mobility species [49]. Interestingly, each form accumulates in $c d c 28-E 217 \mathrm{~V}$ cells, suggesting that $c d c 28-E 217 \mathrm{~V}$ cells are competent to mediate phosphorylation and ubiquitination of Swe1. This is supported by the observation that Cdc28-E217V exhibits normal kinase activity toward histone $\mathrm{H} 1$ and exhibits physical association with Swe1 comparable to wild type Cdc28.

Many CDK substrates are subject to subsequent ubiquitination and proteasome-dependent degradation including cyclins, the stoichiometric inhibitor Sic1, and the securin Pds1 $[59,60]$. Ubiquitination of proteins is mediated by two complexes, the Skp1-cullin-F-box-protein complex (SCF) and the Anaphase-Promoting Complex (APC). Although SCF complex functions at multiple cell cycle transitions, the APC is thought to function only during mitosis. Substrate specificity of each of these complexes is determined in part by F-box subunits for the SCF, and WD-repeat containing proteins for the APC [26,61]. That the Cdc28-Cks1 physical interaction may be important in the downregulation of Swe1, a CDK substrate, suggests that one role of Cks1 may be to recruit the protein degradation machinery to CDK complexes. Such a role has been reported for the mammalian Cks1, which facilitates ubiquitination and degradation of p27, a CDK stoichiometric inhibitor [62].

In yeast, Cks1 and Cdc28 have been reported to interact with the 26S proteasome [30]. Morris and Reed have proposed a model in which Cks1 recruitment of the proteasome and Cdc28 is important for displacement of CDK from specific promoters in a novel mechanism of transcriptional regulation $[29,63]$. Crystal studies of mammalian Cks1 have suggested that Cks1 exists as both a monomer and a multimer, although the regulation and function of this transition is not known [64]. Bourne and Tainer have suggested that Cks1 dimerization forms a pocket which may serve to shuttle phospho-proteins [64]. Further recent evidence has shown that Cks1 interacts directly with monoubiquitin and tetraubiquitin [65]. Together, these findings suggest that Cks1 may facilitate transition of ubiquitinated CDK substrates to the proteasome.

Understanding of events leading to Swe1 degradation however has proven elusive. Kaiser and Reed have shown that the SCF subunit Met30 interacts physically with Swe1 and that met30 mutants exhibit stabilization of Swe 1 protein expressed from an inducible promoter [66]. It is also suggested that in vitro translated Swe1 exhibits lower mobility forms on exposure to whole yeast extract that are dependent on the presence of Met30 [66]. However, studies from the Lew laboratory have shown that deletion of MET30, unlike HSL7, does not enhance the filamentous phenotype caused by deletion of the opposing Tyr19 phosphatase MIH1 [22]. Further, they have also shown 
A
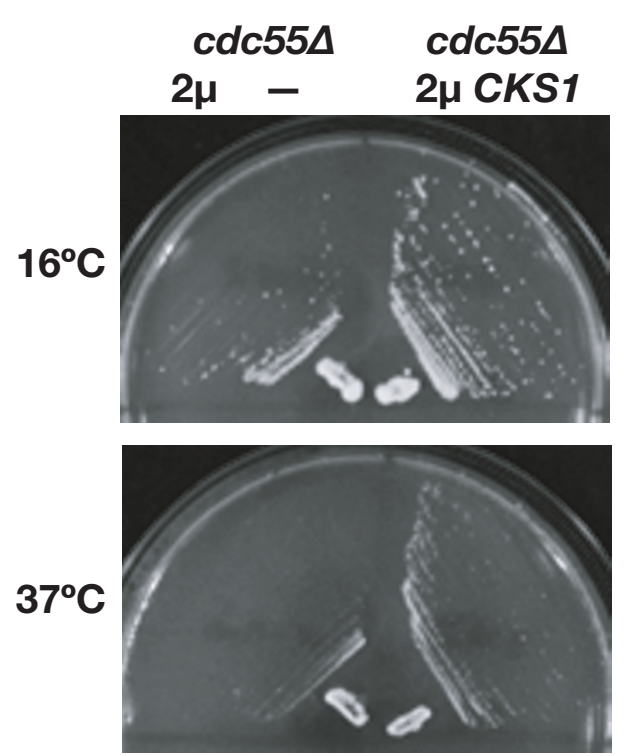

B

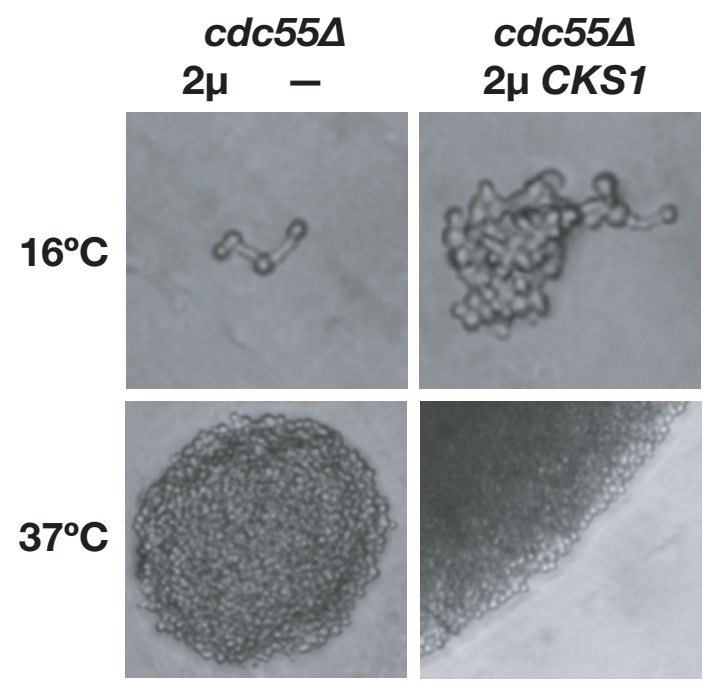

C

$$
\begin{array}{ll}
c d c 55 \Delta & c d c 55 \Delta \\
2 \mu- & 2 \mu C K S 1
\end{array}
$$

anti-Phospho-

Tyr15 Cdc2

anti-PSTAIRE

\section{Figure 7}

Cks I opposes Swe I function in cdc55 mutants. A) Growth and B) Morphology of cdc55 mutants (W303 background) at 16 and $37^{\circ} \mathrm{C}$ transformed with high copy CKSI or empty vector. C) Cdc28 Tyr 19 phosphorylation in cdc55 deletion mutants (W303 background) transformed with high copy CKSI or empty vector. 
that double deletion of MET30 and another SCF subunit MET4 does not stabilize Swe 1 protein levels. To further examine Swe1 regulation, McMillan and colleagues measured Cdc28 tyrosine phosphorylation in the absence of each of 13 deletions of non-essential F-box subunits, none of which showed an appreciable increase [22]. Finally, Kellogg has suggested that Swe1 protein is present throughout mitosis and that degradation may not be a primary mechanism of regulation [49,67]. Our findings support that Swe1 protein levels are subject to regulation that depends on Cks1.

That Cks1 may have a role in regulating protein stability may also explain the genetic interaction of $c d c 28-E 217 \mathrm{~V}$ with the PKA pathway. Bolte and Irniger have found that RAS2-V19 enhances the growth defects of mutants of the APC through a mechanism that depends on activation of adenylate cyclase [24]. Conversely, deletion of RAS2 or overexpression of PDE2 diminishes the growth defects of APC mutants. However, it has also been observed that deletion of RAS2 may have the opposite effect on SCF mutants, actually enhancing growth defects [25].

\section{Conclusion}

Our results indicate that the RAS-mediated PKA pathway and Cks1 are important regulators of Swe1 and, thereby, of Cdc28-Clb2 mitotic function during yeast filamentous growth. The phenotypes of $c d c 28-E 217 \mathrm{~V}$, a mutant deficient for proper Cdc28-Cks1 association, are partly dependent on the presence of PKA pathway components and Swe1. Swe1 accumulates in the $c d c 28-E 217 \mathrm{~V}$ cells supporting prior studies showing that association of Swe1 with Clb2 mediates negative feedback provided by CDK phosphorylation [62]. Overexpression of CKS1 restores near wild-type growth, morphology and Cdc28 Tyr19 phosphorylation to $c d c 55$ mutant cells defective for Swe1 degradation. Future studies elucidating the precise degradation machinery required for Swe1 turnover will be important in understanding the importance of the PKA pathway in regulating Cdc28 CDK activity.

\section{Methods}

\section{Strain construction}

Gene replacement, allele integration, yeast mating, and yeast transformation were as described $[3,68]$. For genetic analyses, multiple tetratypes were examined. Yeast strains were constructed in the Sigma 1278b background unless indicated. Strains and plasmids were derived from the following:

\section{Strains}

SKY750 - MATa/ $\alpha$ cdc28::TRP1/cdc28::TRP1 his3 [pCT3 CDC28 URA3]; SKY768 - MATa clb1::TRP1 ura3; SKY772 - MATa clb2::LEU2 ura3; SKY901 - MAT $\alpha$ swe1::LEU2 ura3; SKY903 - MAT $\alpha$ mih1::LEU2 ura3; SKY985 - MATa
cln1::URA3 cln2::LEU2 trp1; SKY2244 - MAT $\alpha$ ura3 his3 leu2 trp1; SKY2256 - MATa/MATa ura3/ura3 his3/his3 leu2/LEU2 trp1/TRP1; SKY2264 - MATa ura3 his3; SKY2618 - MATa ras2::kanMX6 ura3 his3 leu2; SKY3003 - MATa/MATa cdc28-E217V:kanMX6/cdc28E217V:kanMX6; SKY3004 - MATa/MAT $\alpha$ CDC28/cdc28E217V:kanMX6; SKY3005 - MATa cdc28-E217V:kanMX6 ura3 his3 leu2; SKY3006 - MATa SWE1-13Myc:kanMX6; SKY3007 - MATa flo8::kanMX6 ura3 his3 trp1; SKY3008 - MATa sfl1::kanMX6 his3; SKY3009 - MAT $\alpha$ tec1:kanMX6 ura3 his3; SKY3010 - MATa tpk2::kanMX6 ura3 his3 leu2 trp1; SKY3011 - MATa cdc55::kanMX6 ura3 his3 trp1 (W303); SKY3012 - MATa gen4::HIS3 ura3 leu2

\section{Plasmids}

pSKB4250 - YEplac195 $2 \mu$ URA3 GAL> (gift of M. Solomon); pSKB4251 - YEplac195 $2 \mu$ URA3 GAL>PTC2 (gift of M. Solomon); pSKB4252 - YEplac195 $2 \mu U R A 3$ GAL>PTC3 (gift of M. Solomon); pSKB4253 - pRS202 $2 \mu$ URA3 CLB2; pSKB4254 - pRS $2022 \mu$ URA3 CAK1; pSKB4255 - pRS202 $2 \mu$ URA3 CLN1; pSKB4256 pRS202 $2 \mu$ URA3 CKS1; pSKB4257 - pRS202 $2 \mu$ URA3; pSKB4258 - pCT3 CEN URA3 CDC28; pSKB4259 pGEX-3x-GST-SWE1 [69] (gift of J. Thorner); pSKB4260 pGEX-3x-GST (gift of J. Thorner); pRS413-cdc28 library CEN HIS3

\section{Screen for cdc28 mutants}

A degenerate-PCR derived library of $c d c 28$ mutants cloned into pRS413 was used to transform SKY750 [3]. The transformants were then replica-plated onto 5-Fluoroorotic acid (5-FOA)-containing media to evict the CEN URA3 CDC28 plasmid. About 50,000 5-FOA ${ }^{\mathrm{R}}$ colonies were plated on synthetic low ammonia dextrose (SLAD) media. Five hundred colonies exhibiting enhanced filamentous growth were isolated and from these, 64 showed dramatically reduced growth at $35^{\circ} \mathrm{C}$. Plasmids were rescued and re-introduced in SKY750. After 5-FOA treatment, 39 were found to confer a strong phenotype and were sequenced. Genomic integration of the E217V mutation into SKY2256 was as described [68]. Tetrad analysis and DNA sequencing were used to confirm the integration.

\section{Bioinformatic Analysis}

The effect of polymorphism at E217 was studied as described [38]. Molecular modeling was performed as described [3] using Swiss-Model and Swiss-PDB-Viewer $[70,71]$.

\section{Spot Tests}

Yeast cultures were grown to saturation in rich or selective liquid media at $22^{\circ} \mathrm{C}$. Saturated cultures were diluted serially at a ratio of $1 / 5$ and spotted onto rich or selective agar medium. We have found the cdc 28 mutants, possibly in 
part of because of the essential nature of many Cdc28 functions, have a tendency to acquire genomic and intragenic suppressor mutations. Because of this, we repeated spot testing at least four times for each experiment and a representative assay is shown. Each of the experimental groups shown within a given experiment were performed together on the same plate at each temperature. Images were acquired with a Pixera Professional camera on a Zeiss inverted microscope using brightfield illumination and contrast-enhanced in Adobe Photoshop. Magnification for detail of growth and morphology was performed in accord with previously published assessments of filamentation $[72,73]$.

\section{Biochemical Analyses}

Yeast extracts were prepared from log phase cultures by bead beating in buffer containing $50 \mathrm{mM}$ Tris $\mathrm{pH}$ 7.6, $10 \%$ glycerol, $0.5 \%$ NP-40, 2 mM EDTA, $250 \mathrm{mM} \mathrm{NaCl}, 1$ $\mathrm{mM}$ phenylmethylsulphonyl fluoride, and protease inhibitor cocktail (Roche). Protein content was determined by Bradford assay. For Western blot analysis, proteins separated by SDS-PAGE were transferred to nitrocellulose membranes, and blocked in TBS-Tween-20 containing 5\% milk, or 5\% BSA for anti-phospho-Tyr 15 Cdc2 antibody (Cell Signaling Technologies). Membranes were probed with polyclonal anti-Myc (A14, Santa Cruz) at 1/1000 dilution, anti-PSTAIRE (Santa Cruz) at $1 / 500$, anti-phospho-Tyr15 Cdc2 (Cell Signaling Technologies) at 1/1000, or anti-PGK (Molecular Probes) at 1/2500. Membranes were washed $3 \times$ with TBS-Tween-20 and probed with HRP-linked anti-rabbit or anti-mouse IgG (Amersham) at $1 / 2500$. For p13 Suc1 pull-down reactions, $1 \mathrm{mg}$ of protein extract was incubated overnight at $4{ }^{\circ} \mathrm{C}$ with $50 \mu \mathrm{l}$ of $\mathrm{p} 13^{\text {Sucl }}$ Sepharose bead slurry (Upstate). Beads were washed five times with extract buffer, boiled in sample buffer and the supernatants subjected to SDSPAGE. For binding assays using GST-Swe1 coated glutathione beads, $1 \mathrm{mg}$ of yeast extract was incubated overnight with $100 \mu \mathrm{l}$ of $50 \%$ glutathione bead slurry and treated as for p13 $^{\text {Suc1 }}$ Sepharose beads. GST-Swe1 was isolated from E. coli BL21(DE3) plysS harboring pGEX-GST-SWE1 [69], a kind gift from Jeremy Thorner. Bacteria were grown to an O.D. ${ }_{600}$ of 0.6 , induced for $3 \mathrm{~h}$ at $37^{\circ} \mathrm{C}$ with $0.2 \mathrm{mM}$ IPTG, and briefly sonicated in PBS buffer containing protease inhibitor cocktail, $1 \mathrm{mM}$ PMSF, $1 \mathrm{mM}$ Orthovanadate, $0.5 \mathrm{mM}$ DTT, and 1\% Triton X-100. Glutathione beads were incubated with 1-2 mg of protein extract overnight at $4^{\circ} \mathrm{C}$. GST-Swe1 coated beads were washed five times with PBS and incubated with extracts.

\section{Abbreviations}

(CDK): cyclin-dependent kinase; (SCF): Skp1-cullin-Fbox-protein complex; (PKA): protein kinase A; (MAPK): mitogen-activated protein kinase; (PP2A): protein phos- phatase 2A; (G1): growth phase 1 ; (S): synthesis phase; (G2): growth phase 2; (M): mitosis.

\section{Competing interests}

The authors declare that they have no competing interests.

\section{Authors' contributions}

BT generated the hypotheses and conclusions presented and conducted the genetic and biochemical experiments as well as wrote the manuscript. AK made significant contributions to the conception, design, hypotheses and interpretation of data of all of the studies presented, provided substantial technical assistance and optimization of genetic and biochemical assays, developed a large proportion of the specific reagents for testing of genetic and biochemical interactions of cell cycle genes, and extensively reviewed and revised the manuscript. JS and RG participated in repeating and confirming experimental results, as well as compilation and organization of the data. BB performed the primary screen for temperature sensitive $c d c 28$ alleles. JC provided intellectual contributions, technical support and aided in review and revision of the manuscript. DC conducted bioinformatic analyses of each of the $c d c 28$ alleles. SK conceived the initial study, directed and coordinated all studies, and provided resources and materials for the studies presented.

\section{Acknowledgements}

We thank S. Anderson, B. Nacev, M. Rengarajan, S. Ahn, A. Javaheri, J. Fitz Gerald, S. Palecek, D. Rua, D. Lew, M. Solomon, and J. Thorner for generously providing strains, reagents and expertise. This work was supported by NSF grant MCB $9875976, \mathrm{NIH}$ grant GM60443 and a Leukemia and Lymphoma Society Scholar award to SJK; and NSF grant RIG 07 I 8442 to AAK. BTDT was a trainee of the U. Chicago NIH MST Program and funded by a pre-doctoral grant from the American Heart Association.

\section{References}

I. Lew DJ, Reed SI: A cell cycle checkpoint monitors cell morphogenesis in budding yeast. J Cell Biol 1995, 129:739-749.

2. Ahn SH, Acurio A, Kron SJ: Regulation of G2/M progression by the STE mitogen-activated protein kinase pathway in budding yeast filamentous growth. Mol Biol Cell I999, 10:330I-3316.

3. Ahn SH, Tobe BT, Fitz Gerald JN, Anderson SL, Acurio A, Kron SJ: Enhanced cell polarity in mutants of the budding yeast cyclin-dependent kinase Cdc28p. Mol Biol Cell 200I, I 2:3589-3600.

4. Fitch I, Dahmann C, Surana U, Amon A, Nasmyth K, Goetsch L, Byers B, Futcher B: Characterization of four B-type cyclin genes of the budding yeast Saccharomyces cerevisiae. Mol Biol Cell 1992, 3:805-8I8.

5. Mendenhall MD, Hodge AE: Regulation of Cdc28 cyclin-dependent protein kinase activity during the cell cycle of the yeast Saccharomyces cerevisiae. Microbiol Mol Biol Rev 1998, 62:1191-1243.

6. Ubersax JA, Woodbury EL, Quang PN, Paraz M, Blethrow JD, Shah K, Shokat KM, Morgan DO: Targets of the cyclin-dependent kinase Cdk I. Nature 2003, 425:859-864.

7. Lorenz MC, Cutler NS, Heitman J: Characterization of alcoholinduced filamentous growth in Saccharomyces cerevisiae. Mol Biol Cell 2000, II:183-199.

8. Mosch HU, Kubler E, Krappmann S, Fink GR, Braus GH: Crosstalk between the Ras2p-controlled mitogen-activated protein kinase and cAMP pathways during invasive growth of Saccharomyces cerevisiae. Mol Biol Cell 1999, 10:1325-1335. 
9. Gancedo JM: Control of pseudohyphae formation in Saccharomyces cerevisiae. FEMS Microbiol Rev 200I, 25: I07-I 23.

10. Gustin MC, Albertyn J, Alexander M, Davenport K: MAP kinase pathways in the yeast Saccharomyces cerevisiae. Microbiol Mol Biol Rev 1998, 62:1264-1300.

II. Gavrias V, Andrianopoulos A, Gimeno C], Timberlake WE: Saccharomyces cerevisiae $T E C I$ is required for pseudohyphal growth. Mol Microbiol 1996, 19:1255-1263.

12. Robertson LS, Fink GR: The three yeast $\mathbf{A}$ kinases have specific signaling functions in pseudohyphal growth. Proc Natl Acad Sci USA 1998, 95:13783-13787.

13. Pan X, Heitman J: Protein kinase A operates a molecular switch that governs yeast pseudohyphal differentiation. Mol Cell Biol 2002, 22:398I-3993.

14. Fujita A, Kikuchi Y, Kuhara S, Misumi Y, Matsumoto S, Kobayashi H: Domains of the SFLI protein of yeasts are homologous to Myc oncoproteins or yeast heat-shock transcription factor. Gene 1989, 85:321-328.

15. Nikawa J, Sass P, Wigler M: Cloning and characterization of the low-affinity cyclic AMP phosphodiesterase gene of Saccharomyces cerevisiae. Mol Cell Biol 1987, 7:3629-3636.

16. Sass P, Field J, Nikawa J, Toda T, Wigler M: Cloning and characterization of the high-affinity cAMP phosphodiesterase of Saccharomyces cerevisiae. Proc Natl Acad Sci USA 1986, 83:9303-9307.

17. McMillan JN, Sia RA, Bardes ES, Lew DJ: Phosphorylation-independent inhibition of Cdc28p by the tyrosine kinase Swe Ip in the morphogenesis checkpoint. Mol Cell Biol 1999, 19:598I-5990.

18. La Valle R, Wittenberg C: A role for the Swe I checkpoint kinase during filamentous growth of Saccharomyces cerevisiae. Genetics 200I, 158:549-562

19. Booher RN, Deshaies RJ, Kirschner MW: Properties of Saccharomyces cerevisiae Weel and its differential regulation of p34CDC28 in response to $\mathbf{G I}$ and $\mathbf{G 2}$ cyclins. EMBO J 1993, I 2:34|7-3426.

20. Schulze-Gahmen U, De Bondt HL, Kim SH: High-resolution crystal structures of human cyclin-dependent kinase 2 with and without ATP: bound waters and natural ligand as guides for inhibitor design. J Med Chem 1996, 39:4540-4546.

21. Harvey SL, Charlet A, Haas W, Gygi SP, Kellogg DR: Cdk I-dependent regulation of the mitotic inhibitor Weel. Cell 2005, 1 22:407-420.

22. McMillan JN, Theesfeld CL, Harrison JC, Bardes ES, Lew DJ: Determinants of Swe Ip degradation in Saccharomyces cerevisiae. Mol Biol Cell 2002, 13:3560-3575.

23. McMillan JN, Longtine MS, Sia RA, Theesfeld CL, Bardes ES, Pringle JR, Lew DJ: The morphogenesis checkpoint in Saccharomyces cerevisiae: cell cycle control of Swe lp degradation by HsI lp and Hsi7p. Mol Cell Biol 1999, 19:6929-6939.

24. Bolte M, Dieckhoff P, Krause C, Braus GH, Irniger S: Synergistic inhibition of $\mathrm{APC} / \mathrm{C}$ by glucose and activated Ras proteins can be mediated by each of the TpkI-3 proteins in Saccharomyces cerevisiae. Microbiology 2003, 149:1205-1216.

25. Irniger S, Baumer M, Braus GH: Glucose and ras activity influence the ubiquitin ligases $A P C / C$ and SCF in Saccharomyces cerevisiae. Genetics 2000, 154:1509-152I.

26. Vodermaier HC: APC/C and SCF: controlling each other and the cell cycle. Curr Biol 2004, I 4:R787-796.

27. Heo SJ, Tatebayashi $\mathrm{K}$, Ikeda $\mathrm{H}$ : The budding yeast cohesin gene SCCIIMCDI/RHC2I genetically interacts with PKA, CDK and APC. Curr Genet 1999, 36:329-338.

28. Rudner AD, Murray AW: Phosphorylation by Cdc28 activates the Cdc20-dependent activity of the anaphase-promoting complex. J Cell Biol 2000, I 49: I377-1390.

29. Morris MC, Kaiser P, Rudyak S, Baskerville C, Watson MH, Reed SI: CksI-dependent proteasome recruitment and activation of CDC20 transcription in budding yeast. Nature 2003, 423: $1009-1013$.

30. Kaiser P, Moncollin V, Clarke DJ, Watson MH, Bertolaet BL, Reed SI, Bailly E: Cyclin-dependent kinase and Cks/Sucl interact with the proteasome in yeast to control proteolysis of M-phase targets. Genes Dev 1999, I3: I 190-1202.

31. Tang Y, Reed SI: The Cdk-associated protein Cks I functions both in GI and G2 in Saccharomyces cerevisiae. Genes Dev 1993, 7:822-832
32. Reynard GJ, Reynolds W, Verma R, Deshaies RJ: Cks I is required for $\mathbf{G}(\mathrm{I})$ cyclin-cyclin-dependent kinase activity in budding yeast. Mol Cell Biol 2000, 20:5858-5864.

33. Schulze-Gahmen U, Brandsen J, Jones HD, Morgan DO, Meijer L, Vesely J, Kim SH: Multiple modes of ligand recognition: crystal structures of cyclin-dependent protein kinase 2 in complex with ATP and two inhibitors, olomoucine and isopentenyladenine. Proteins 1995, 22:378-391.

34. Morgan DO: The dynamics of cyclin dependent kinase structure. Curr Opin Cell Biol 1996, 8:767-772.

35. De Bondt HL, Rosenblatt J, Jancarik J, Jones HD, Morgan DO, Kim SH: Crystal structure of cyclin-dependent kinase 2. Nature 1993, 363:595-602.

36. Pavletich NP: Mechanisms of cyclin-dependent kinase regulation: structures of Cdks, their cyclin activators, and Cip and INK4 inhibitors. J Mol Biol 1999, 287:82I-828

37. Bourne $\mathrm{Y}$, Watson MH, Hickey MJ, Holmes W, Rocque W, Reed SI, Tainer JA: Crystal structure and mutational analysis of the human CDK2 kinase complex with cell cycle-regulatory protein CksHsI. Cell 1996, 84:863-874.

38. Chasman D, Adams RM: Predicting the functional consequences of non-synonymous single nucleotide polymorphisms: structure-based assessment of amino acid variation. J Mol Biol 200I, 307:683-706.

39. Song H, Hanlon N, Brown NR, Noble ME, Johnson LN, Barford D: Phosphoprotein-protein interactions revealed by the crystal structure of kinase-associated phosphatase in complex with phosphoCDK2. Mol Cell 200I, 7:6I5-626.

40. Ross KE, Kaldis P, Solomon MJ: Activating phosphorylation of the Saccharomyces cerevisiae cyclin-dependent kinase, Cdc28p, precedes cyclin binding. Mol Biol Cell 2000, I I:1597-1609.

4I. Brown NR, Noble ME, Endicott JA, Johnson LN: The structural basis for specificity of substrate and recruitment peptides for cyclin-dependent kinases. Nat Cell Biol 1999, I:438-443.

42. Cheng A, Ross KE, Kaldis P, Solomon MJ: Dephosphorylation of cyclin-dependent kinases by type $2 \mathrm{C}$ protein phosphatases. Genes Dev 1999, 13:2946-2957.

43. Pan X, Harashima T, Heitman J: Signal transduction cascades regulating pseudohyphal differentiation of Saccharomyces cerevisiae. Curr Opin Microbiol 2000, 3:567-572.

44. Lorenz MC, Heitman J: Yeast pseudohyphal growth is regulated by GPA2, a G protein alpha homolog. EMBO J 1997, 16:7008-7018.

45. Kubler E, Mosch HU, Rupp S, Lisanti MP: Gpa2p, a G-protein alpha-subunit, regulates growth and pseudohyphal development in Saccharomyces cerevisiae via a cAMP-dependent mechanism. J Biol Chem 1997, 272:2032I-20323.

46. Braus GH, Grundmann O, Bruckner S, Mosch HU: Amino acid starvation and Gcn4p regulate adhesive growth and FLOII gene expression in Saccharomyces cerevisiae. Mol Biol Cell 2003, 1 4:4272-4284.

47. Pan X, Heitman J: Cyclic AMP-dependent protein kinase regulates pseudohyphal differentiation in Saccharomyces cerevisiae. Mol Cell Biol 1999, 19:4874-4887.

48. Hodge A, Mendenhall M: The cyclin-dependent kinase inhibitory domain of the yeast Sicl protein is contained within the C-terminal 70 amino acids. Mol Gen Genet 1999, 262:55-64.

49. Harvey SL, Kellogg DR: Conservation of mechanisms controlling entry into mitosis: budding yeast weel delays entry into mitosis and is required for cell size control. Curr Biol 2003, 13:264-275.

50. Yang H, Jiang W, Gentry M, Hallberg RL: Loss of a protein phosphatase $2 A$ regulatory subunit $(\mathrm{Cdc55p})$ elicits improper regulation of Swelp degradation. Mol Cell Biol 2000, 20:8I43-8I56.

51. Cherkasova VA, McCully R, Wang Y, Hinnebusch A, Elion EA: A novel functional link between MAP kinase cascades and the Ras/cAMP pathway that regulates survival. Curr Biol 2003, 13:1220-1226.

52. Kim TS, Kim HY, Yoon JH, Kang HS: Recruitment of the Swi/Snf complex by Stel2-Tecl promotes Flo8-Mss I I-mediated activation of STA I expression. Mol Cell Biol 2004, 24:9542-9556.

53. Elion EA: Pheromone response, mating and cell biology. Curr Opin Microbiol 2000, 3:573-58I. 
54. Peter M, Herskowitz I: Direct inhibition of the yeast cyclindependent kinase Cdc28-Cln by Farl. Science 1994, 265: $|228-| 23 \mid$.

55. Jeoung DI, Oehlen LJ, Cross FR: Cln3-associated kinase activity in Saccharomyces cerevisiae is regulated by the mating factor pathway. Mol Cell Biol 1998, 18:433-44I.

56. Gartner A, Jovanovic A, Jeoung DI, Bourlat S, Cross FR, Ammerer G Pheromone-dependent $\mathrm{GI}$ cell cycle arrest requires Far $\mathrm{I}$ phosphorylation, but may not involve inhibition of Cdc28Cln2 kinase, in vivo. Mol Cell Biol 1998, 18:368I-369|.

57. Henchoz S, Chi Y, Catarin B, Herskowitz I, Deshaies RJ, Peter M: Phosphorylation- and ubiquitin-dependent degradation of the cyclin-dependent kinase inhibitor Far I p in budding yeast. Genes Dev 1997, I I:3046-3060.

58. Hu F, Gan Y, Aparicio OM: Identification of $\mathrm{Clb2}$ residues required for Swel regulation of Clb2-Cdc28 in Saccharomyces cerevisiae. Genetics 2008, 179:863-874.

59. Santamaria PG, Finley D, Ballesta JP, Remacha M: Rpn6p, a proteasome subunit from Saccharomyces cerevisiae, is essential for the assembly and activity of the $26 \mathrm{~S}$ proteasome. J Biol Chem 2003, 278:6687-6695.

60. Verma R, Annan RS, Huddleston MJ, Carr SA, Reynard G, Deshaies RJ: Phosphorylation of Siclp by GI Cdk required for its degradation and entry into $S$ phase. Science 1997, 278:455-460.

61. Peters JM: SCF and APC: the Yin and Yang of cell cycle regulated proteolysis. Curr Opin Cell Biol 1998, 10:759-768.

62. Wang W, Ungermannova $D$, Chen L, Liu X: A negatively charged amino acid in Skp2 is required for Skp2-CksI interaction and ubiquitination of p27 Kip I. J Biol Chem 2003, 278:32390-32396.

63. Yu VP, Baskerville C, Grunenfelder B, Reed SI: A kinase-independent function of Cks I and CdkI in regulation of transcription. Mol Cell 2005, I7:|45-I5I.

64. Bourne Y, Watson MH, Arvai AS, Bernstein SL, Reed SI, Tainer JA: Crystal structure and mutational analysis of the Saccharomyces cerevisiae cell cycle regulatory protein Cks I: implications for domain swapping, anion binding and protein interactions. Structure 2000, 8:84|-850.

65. Tempe D, Brengues M, Mayonove P, Bensaad H, Lacrouts C, Morris MC: The alpha helix of ubiquitin interacts with yeast cyclindependent kinase subunit CKSI. Biochemistry 2007, 46:45-54.

66. Kaiser P, Sia RA, Bardes EG, Lew DJ, Reed SI: Cdc34 and the F-box protein Met30 are required for degradation of the Cdk-inhibitory kinase Swe I. Genes Dev 1998, I 2:2587-2597.

67. Kellogg DR: Weel-dependent mechanisms required for coordination of cell growth and cell division. I Cell Sci 2003, I 1 6:4883-4890.

68. Kitazono AA, Tobe BT, Kalton H, Diamant N, Kron SJ: Markerfusion PCR for one-step mutagenesis of essential genes in yeast. Yeast 2002, 19:14I-149.

69. Cid VJ, Shulewitz MJ, McDonald KL, Thorner J: Dynamic localization of the Swel regulator Hsl7 during the Saccharomyces cerevisiae cell cycle. Mol Biol Cell 200I, I 2:1645-1669.

70. Guex N, Peitsch MC: SWISS-MODEL and the Swiss-PdbViewer: an environment for comparative protein modeling. Electrophoresis 1997, 18:27।4-2723.

7I. Schwede T, Kopp J, Guex N, Peitsch MC: SWISS-MODEL: An automated protein homology-modeling server. Nucleic Acids Res 2003, 31:338I-3385.

72. Lorenz MC, Heitman J: Regulators of pseudohyphal differentiation in Saccharomyces cerevisiae identified through multicopy suppressor analysis in ammonium permease mutant strains. Genetics 1998, I50: 1443-1457.

73. Madhani HD, Fink GR: Combinatorial control required for the specificity of yeast MAPK signaling. Science 1997, 275: $13 \mid 4-1317$

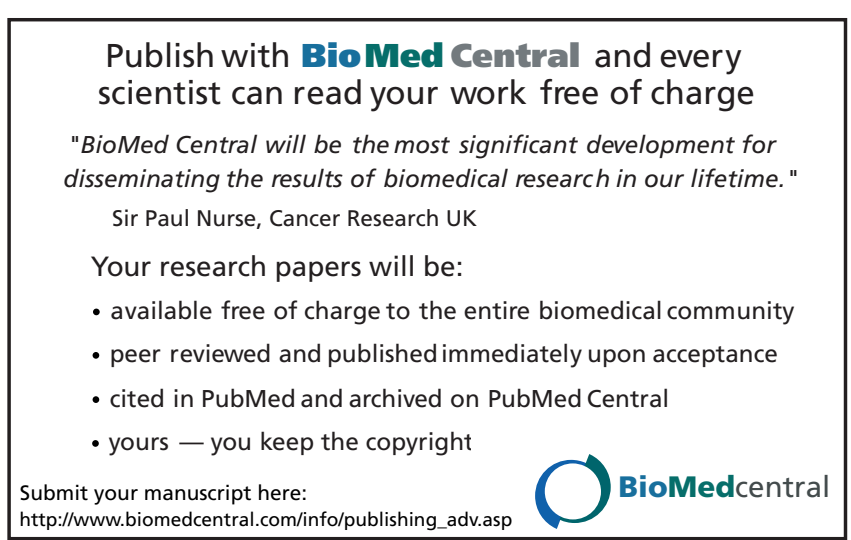

